\title{
Excessive morphine requirements after pre-hospital nalbuphine analgesia
}

\author{
K P G Houlihan, R G Mitchell, A D Flapan, D J Steedman
}

\begin{abstract}
Nalbuphine hydrochloride is an opioid agonist-antagonist that has gained acceptance as a pre-hospital analgesic agent. Nalbuphine has equal analgesic properties to morphine, has a low addiction potential, and can be stored and administered without restrictions, unlike morphine. To date no clinical evidence has been published to support the theoretical difficulty that the action of opioids administered after nalbuphine could be altered or negated. The following case reports highlight 10 patients who received nalbuphine pre-hospital and subsequently required higher doses of opioid analgesia than expected. The discussion summarises the properties of nalbuphine and identifies potential reasons why excessive amounts of opioid analgesia were required. $(\Im$ Accid Emerg Med 1999;16:29-31)
\end{abstract}

Keywords: nalbuphine; opioid; analgesia; pre-hospital

The benefits of early analgesia in both medical and trauma patients are well established. ${ }^{1}$ The ideal analgesic in the pre-hospital phase would provide adequate analgesia, could be rapidly and safely administered with the minimum of side effects, and would not adversely affect the subsequent clinical course of patients after admission to hospital.

Nalbuphine hydrochloride is an agonistantagonist opioid, with equipotent analgesic properties to morphine. ${ }^{2}$ In contrast to morphine, nalbuphine demonstrates a "ceiling" effect on respiratory depression and has low addiction potential. ${ }^{3}$ It is not a controlled drug and therefore can be stored and administered without restrictions, unlike morphine. Nalbuphine acts as a competitive antagonist at the $\mu$ opioid receptor while simultaneously acting as an agonist at the $\kappa$ receptor. Therefore it is possible that the action of opioids subsequently administered could be altered or negated. Chambers and Guly found no clinical evidence to support the theoretical difficulty that nalbu- phine counteracted the analgesic properties of other opioid agents. ${ }^{4}$ To date all clinical data supports the opinion that this potentially adverse effect does not occur in practice and nalbuphine has now gained wide acceptance as a valued pre-hospital analgesic. ${ }^{56}$

The following case reports describe two patients in detail and highlight eight others who received nalbuphine out of hospital and subsequently required higher doses of opioid analgesia than expected during the early period after admission. The discussion outlines the properties of nalbuphine and identifies potential reasons why subsequent excessive amounts of opioid analgesia were necessary.

\section{Case reports}

CASE 1: ACUTE INFERIOR MYOCARDIAL INFARCTION

A 40 year man collapsed at home after an episode of severe chest pain. The attending ambulance crew administered buccal Suscard $2 \mathrm{mg}$ sublingually, aspirin $300 \mathrm{mg}$ orally, and $6 \mathrm{mg}$ of nalbuphine intravenously. The diagnosis of acute inferior myocardial infarction was confirmed on a 12 lead electrocardiogram (ECG) in the accident and emergency (A\&E) department. After thrombolysis in the coronary care unit, the ECG changes resolved but his pain persisted and he required $50 \mathrm{mg}$ Cyclimorph, in $10 \mathrm{mg}$ increments over a 105 minute period. The initial dose of morphine was given 52 minutes after the administration of nalbuphine. The patient was pain free 2 hours and 57 minutes after his pre-hospital analgesia. His pain was subsequently controlled with oral paracetamol.

CASE 2: VERTEBRAL FRACTURE

A 37 year old man presented to the $A \& E$ department having fallen approximately 20 feet through a skylight. At scene he was complaining of back pain with reduced sensation in both legs. The primary survey was unremarkable and he was given $10 \mathrm{mg}$ of nalbuphine by slow intravenous injection. This allowed the ambulance crew to secure adequate immobilisation before transfer to

Accepted 27 June 1998

Table 1 Intravenous nalbuphine administration and subsequent opioid requirements in cardiac patients

\begin{tabular}{|c|c|c|c|c|c|c|c|c|c|c|c|}
\hline \multirow{2}{*}{$\begin{array}{l}\text { Case } \\
\text { No }\end{array}$} & \multirow{2}{*}{$\begin{array}{l}\text { Age } \\
\text { (years) }\end{array}$} & \multirow[b]{2}{*}{ Sex } & \multirow[b]{2}{*}{ Diagnosis } & \multirow{2}{*}{$\begin{array}{l}\text { Dose of } \\
\text { nalbuphine } \\
\text { pre-hospital } \\
\text { (mg) }\end{array}$} & \multicolumn{5}{|c|}{$\begin{array}{l}\text { Subsequent dose (mg) of morphine: time after nalbuphine } \\
\text { (min) }\end{array}$} & \multirow{2}{*}{$\begin{array}{l}\text { Total } \\
\text { morphine } \\
\text { (mg) (iv) }\end{array}$} & \multirow[b]{2}{*}{ Other treatment } \\
\hline & & & & & $0-30$ & $31-60$ & $61-90$ & $91-120$ & $121-300$ & & \\
\hline $1 \mathrm{M}$ & 40 & $\mathbf{M}$ & Inferior MI & 6 & - & 10 & - & 20 & 20 & 50 & Thrombolysis \\
\hline $2 \mathrm{M}$ & 50 & $M$ & Inferior MI & 12 & 10 & 5 & 10 & 10 & - & 35 & Thrombolysis \\
\hline $3 M$ & 53 & $\mathbf{F}$ & Unstable angina & 17 & 5 & 30 & - & - & - & 35 & Nitrocine/heparin iv \\
\hline $4 M$ & 52 & $\mathbf{F}$ & Unstable angina & 20 & - & 10 & 10 & - & 20 & 40 & Nitrocine/heparin iv \\
\hline $5 \mathrm{M}$ & 29 & $\mathbf{M}$ & Anterior MI & 10 & 20 & 20 & 20 & 10 & - & 70 & Thrombolysis \\
\hline
\end{tabular}

iv = intravenous; $\mathrm{MI}=$ myocardial infarction. 
Table 2 Intravenous nalbuphine administration and subsequent opioid requirements in trauma cases

\begin{tabular}{|c|c|c|c|c|c|c|c|c|c|c|c|}
\hline \multirow{2}{*}{$\begin{array}{l}\text { Case } \\
\text { No }\end{array}$} & \multirow{2}{*}{$\begin{array}{l}\text { Age } \\
\text { (years) }\end{array}$} & \multirow[b]{2}{*}{ Sex } & \multirow[b]{2}{*}{ Diagnosis } & \multirow{2}{*}{$\begin{array}{l}\text { Dose of } \\
\text { nalbuphine } \\
\text { pre-hospital } \\
\text { (mg) }\end{array}$} & \multicolumn{5}{|c|}{$\begin{array}{l}\text { Subsequent dose (mg) of morphine: time after } \\
\text { nalbuphine (min) }\end{array}$} & \multirow{2}{*}{$\begin{array}{l}\text { Total } \\
\text { morphine } \\
\text { (mg) (iv) }\end{array}$} & \multirow[b]{2}{*}{ Other treatment } \\
\hline & & & & & $0-30$ & $31-60$ & $61-90$ & $91-120$ & $121-300$ & & \\
\hline $1 \mathrm{~T}$ & 37 & $\mathbf{M}$ & \#T12/L1 & 10 & 30 & 10 & - & - & - & 40 & $4.5 \mathrm{mg}$ diazepam iv \\
\hline $2 \mathrm{~T}$ & 20 & F & \#Tibia/fibula & 10 & 10 & 10 & - & - & 10 & 30 & $5 \mathrm{mg}$ midazolam iv \\
\hline $3 \mathrm{~T}$ & 25 & $\mathbf{M}$ & \#Tibia/fibula & 10 & 20 & 10 & 5 & - & - & 35 & $15 \mathrm{mg}$ diazemuls iv \\
\hline $4 \mathrm{~T}$ & 27 & $\mathbf{M}$ & Dislocated shoulder & 10 & 10 & 5 & - & - & - & 15 & $10 \mathrm{mg}$ midazolam iv \\
\hline $5 \mathrm{~T}$ & 48 & $\mathrm{M}$ & \#L1/\#pelvis/\#scaphoid & 20 & - & 15 & 25 & 8 & - & 48 & Patient controlled morphine iv \\
\hline
\end{tabular}

iv = intravenous; $\#$ = fracture.

hospital. During his A\&E assessment his pain persisted and he required a total of $40 \mathrm{mg}$ of Cyclimorph in $10 \mathrm{mg}$ doses at $15,19,25$, and 35 minutes after the time of administration of nalbuphine. Radiological investigation revealed burst fractures of the 12th thoracic (T12) and first lumbar (L1) vertebrae. In addition to his opioid analgesia, he was sedated with $4.5 \mathrm{mg}$ of diazemuls intravenously. No further opioid analgesia was required within the next 12 hours.

Table 1 and table 2 illustrate the opioid requirements of 10 patients who received nalbuphine out of hospital.

\section{Discussion}

The Scottish Ambulance Service (SAS) introduced nalbuphine as a pre-hospital analgesic agent in April 1995. ${ }^{7}$ The guidelines at that time recommended the administration of a 10 mg dose over five minutes to relieve moderate to severe pain in cases of chest pain, musculoskeletal trauma, burns, and ureteric colic. After careful consideration this was increased to a maximum dose of $20 \mathrm{mg}$ in August 1996. Since the introduction of nalbuphine, it has gained acceptance as a satisfactory analgesic with few side effects in the majority of patients.

The decision to introduce nalbuphine as a pre-hospital analgesic has been based on both animal and human studies. Research has shown that nalbuphine is an agonist-antagonist opioid, which is equal in analgesic potency to morphine, and approximately one third as potent as naloxone as a narcotic antagonist. ${ }^{8}$ Pharmokinetic data on human subjects is limited. However it is suggested that peak concentrations occur 30 minutes after intramuscular injection of $10 \mathrm{mg}$ in healthy individuals with an elimination half life of about 2-5 hours. ${ }^{9}$ Nalbuphine undergoes largely first pass biometabolism and systemic clearance decreases with age. $^{10}$

The effects of this agent have been well documented. While exhibiting equal analgesic potency to morphine, the associated respiratory depression appears to reach a level beyond which further depression does not easily occur. It has similar haemodynamic effects to morphine but after a standard dose of $10 \mathrm{mg}$, there is no associated hypotension or significant bradycardia. ${ }^{11}$ The risk of physical dependence is less and there is a low incidence of dysphoric side effects. ${ }^{12}$ The recognised antagonistic effect is demonstrated by its ability to reverse oxymorphone or fentanyl induced postoperative respiratory depression. ${ }^{13}$
The diverse effects of this drug are explained by complex actions at opioid receptor level. The "multiple receptor" theory, first attributed to Martin et al, ${ }^{14}$ initiated research which subsequently described the existence of $\mu, \kappa, \delta$, and $\sigma$ receptors. Nalbuphine is considered to be a pure or competitive antagonist at the $\mu$ receptor (analgesia, euphoria, depressed respiration, high dependence potential) and an agonist at the $\kappa$ receptor (analgesia, sedation, low addiction liability). It has negligible affinity for $\sigma$ receptors (dysphoria, psychosis). ${ }^{15}$

The potential of antagonising other opioid receptors has been recognised but to date this has not generated clinical problems. The cases highlighted in this report illustrate a series of interesting observations. All patients were administered nalbuphine before arrival in hospital in order to achieve analgesia, to facilitate splintage, and to permit transportation. All were noted to have moderate to severe pain, which necessitated further opioid analgesia during initial assessment. To date, there is no agreement on "normal" analgesic requirements in trauma patients and administration of opioids is based on observation and clinical experience. These patients were judged to require higher than expected doses of opioid analgesia for their age and size by the attending medical staff. However no adjustment for mean body index was made. The group of patients described cover a range of age groups and disease aetiologies. None had been taking regular opioid-like medication before admission, although two patients (cases $2 \mathrm{~T}$ and $5 \mathrm{~T}$ ) were on regular benzodiazepines. The three cardiac patients with documented myocardial infarction had successful thrombolysis as judged by the reversal of the ST changes. The resolution of ST segment elevation after successful thrombolysis is usually associated with cessation of pain. These three patients (cases $1 \mathrm{M}, 2 \mathrm{M}$, and $5 \mathrm{M})$ required excessive analgesia despite thrombolysis resulting in normalisition of the ST segments. This persistence of pain may have been associated with additional catecholamine release in these patients and theoretically added an increased risk of arrhythmias. In practice this was not observed.

These cases may simply represent a group of patients with a higher than expected analgesic requirement. However nine of the 10 patients reverted to expected analgesic requirements within four hours of the administration of nalbuphine. These patients may have been administered subtherapeutic doses of nalbuphine. However the dosages involved were titrated and delivered to accepted protocols 
and all patients were observed to be suitable for transfer without further intervention. Alternatively these patients may represent a group with abnormal nalbuphine and/or morphine metabolism. The cardiac patients undoubtedly exhibited abnormal cardiovascular status but none had documented hepatic dysfunction. Similarly none of the trauma patients were noted to have abnormal liver function. The potential complications of opioid delivery are well established and present risks to the patient. Of the 10 patients described here, one required emergency reversal of his opioid due to acute respiratory depression (case $5 \mathrm{~T}$ ).

The authors acknowledge that these observations are subjective and are not supported by objective physiological measurements or recognised pain scoring. Our observations have been drawn to the attention of the SAS and undoubtedly greater and more accurate data are needed. At the time of completion of this report, the data were insufficient as to the total number of patients administered nalbuphine pre-hospital and their subsequent clinical course. To address this need the SAS is retrospectively examining all data on the administration of nalbuphine since its introduction in 1995. Simultaneously all cardiac patients are being prospectively studied for their analgesic requirements after nalbuphine administration. If such studies confirm a more widespread problem then it will be necessary to review the current policy of pre-hospital analgesia administration.
Our thanks to Ms Jill Laing of the Scottish Ambulance Service for her help in this work.

1 Mathewson ZM, McLoskey BG, Evans AE, et al. Mobile coronary care and community mortality from myocardial infarction. Lancet 1985;i:441.

2 Errick JK, Heel RC. Nalbuphine-a preliminary review of its pharmacological properties and therapeutic efficacy. Drugs 1983;26:191-211.

3 Bovill JG. Which potent opioid? Important criteria for selection. Drugs 1987;33:520-30.

4 Chambers JA, Guly HR. Prehospital intravenous nalbuphine administered by paramedics. Resuscitation 1994;27: 153-8.

5 Stene JK, Stofberg L, MacDonald G, et al. Nalbuphine analgesia in the prehospital setting. Am f Emerg Med 1988; 6:634-9.

6 Johnson GS, Guly HR. The effect of pre-hospital administration of intravenous nalbuphine on on-scene times. $\mathcal{F}$ Accid Emerg Med 1995;12:20-2.

7 Scottish Ambulance Service. Nalbuphine. Standard operating procedure. Edinburgh: SAS, August 1996.

8 Jasinki DR. Opiod receptors and classification. In: Nimmo WS, Smith G, eds. Opioid agonist/antagonist drugs in clinical practice. Oxford: Excerpta Medica, 1984.

9 Beaver WT, Feise GA. A comparison of the analgesic effects of intramuscular nalbuphine and morphine in patients with postoperative pain. I Pharmacol Exp Ther 1978;204:487postop.

10 Jaillon P, Gardin ME, Lecocq B, et al. Pharmokinetics of nalbuphine in infants, young healthy volunteers and elderly patients. Clin Pharmacol Ther 1989;46:226-33.

11 Lee G, Low RI, Amsterdam EA, et al. Haemodynamic effects of morphine and nalbuphine in acute myocardial infarction. Clin Pharmacol Ther 1981;29:576-81.

12 Schmidt WK, Tam SW, Shotzberger GS, et al. Nalbuphine [review]. Drug Alcohol Depend 1985;14:339-62.

13 Magruder MR, Delaney RD, DiFazio CA. Reversal of narcotic-induced respiratory depression with nalbuphine hydrochloride. Anesthesiology Review 1982;9:34.

14 Martin WR, Eades CG, Thompson JA, et al. The effects of morphine- and nalorphine-like drugs in the nondependent and morphine-dependent chronic spinal dog. $\mathcal{F}$ Pharmacol Exp Ther 1976;197:517.

15 Latasch L, Christ R. Opiate receptors [review]. Anaesthesist 1986;32:55-65. 